\title{
Neuroimaging of corpus callosum in central nervous system demyelinating disorders
}

\author{
Masoud Etemadifar ${ }^{1}$, Amir Neshatfar ${ }^{2}$, Amir Arsalan Zamani $^{3}$, Mehri Salari $^{1}$ \\ ${ }^{I}$ Department of Neurology, Alzahra General Hospital, Isfahan University of Medical Sciences, Isfahan 8174675731, Iran. \\ ${ }^{2}$ Multiple Sclerosis and Neuro-Immunology Research Center, Isfahan 8174675731, Iran. \\ ${ }^{3}$ Department of Radiology, Harvard University, Cambridge, MA 02138, USA.
}

Correspondence to: Dr. Amir Neshatfar, Multiple Sclerosis and Neuro-Immunology Research Center, Isfahan 8174675731, Iran.

E-mail: amir_date3@yahoo.com

How to cite this article: Etemadifar M, Neshatfar A, Zamani AA, Salari M. Neuroimaging of corpus callosum in central nervous system demyelinating disorders. Neuroimmunol Neuroinflammation 2017;4:69-77.

\section{Article history: \\ Received: 12-01-2017 \\ Accepted: 18-04-2017 \\ Published: 27-04-2017}

Key words:

Corpus callosum, central nervous system, demyelinating diseases, neuroimaging, review

\begin{abstract}
Corpus callosum (CC) is the largest white matter structure in the brain, consisting of 200250 million contralateral axonal projections. It is the major commissural pathway connecting the hemispheres of human brain. The pathology of CC includes wide variety of entities that arise from different causes such as congenital, inflammatory, tumoral, degenerative, infectious, etc. This study reviews the most reliable neuroimaging data of human CC in central nervous system (CNS) demyelinating diseases to facilitate the understanding of different pathological entities of the $\mathrm{CC}$ and their role in anticipation of probable prognostic findings. After a brief description of normal anatomy and functions of $\mathrm{CC}$, this review examines the most valuable findings obtained using conventional and functional magnetic resonance imaging. It also demonstrates the most well organized findings of how $\mathrm{CC}$ features influence prognostic factors of demyelinating disorders, which could have a great value for choosing proper therapy methods. The authors also provided a brief review of other demyelinating disorders which are primarily caused by other pathological factors other than autoimmunity. As a conclusion, the authors showed the importance of CC as an critical part of the brain, which should be explored by different methods of imaging, correspondent to clinical evaluation of CNS demyelinating disorder to widen our knowledge on pathology and clinical patterns of such disorders.
\end{abstract}

\section{INTRODUCTION}

Corpus callosum (CC) is the largest fiber bundle that connects cortical and subcortical regions of the brain. It also interconnects both cerebral hemispheres, promoting functional integration of sensory and motor functions. The CC is composed of many different fiber types, with varied thickness and myelin sheath variations. The callosal tracts are frequently affected in patients with multiple sclerosis (MS) and other demyelinating disorders such as acute disseminated encephalomyelitis (ADEM), Devic's neuromyelitis optica, marchiafava bignami (MBD), etc. Magnetic resonance imaging (MRI) is the gold standard imaging 
of demyelinating lesions of callosal tract, however there are microstructural pathologic alterations in the CC that cannot be assessed with conventional MRI. Furthermore, in some demyelinating diseases including MS, normal appearing white matter (NAWM) has been reported to have noticeable histological abnormality. ${ }^{[1]}$ Advanced MRI techniques such as diffusion tensor imaging (DTI) and MR spectroscopy have been employed to evaluate changes in NAWM and histological changes in active lesional areas. ${ }^{[2,3]}$ The DTI is an advanced MR imaging technique that provides quantitative information regarding structural features of central nervous system (CNS). It allows the calculation of many parameters, including: mean diffusivity, which is a directionally averaged measurement of the apparent diffusion coefficient (ADC) and fractional anisotropy (FA), which summarizes the orientation-based dependence of diffusivity. ${ }^{[4]}$ Many authors have investigated pathologic features of $\mathrm{CC}$ in different demyelinating diseases through various imaging methods, especially MR imaging. They mostly focused on functional MRI, DTI, MR spectroscopy in recent years of research. This study aimed to provide a short review of different pathologic features of $\mathrm{CC}$ in neuroimaging of demyelinating disorders of CNS, which are mostly auto-inflammatory types. It also shows the role of these features in prognosis of these disorders to help further discrimination and comparison between such diseases. ${ }^{[5,6]}$ Cognitive dysfunction is one of the major factors affecting the social functioning and quality of life of patients suffering from demyelinating disorders especially MS patients and It is one of the most important factors which can be closely related to neuroimaging features of MS. This can play a keyrole to help determine the outcome of the disease and also their response to possible routine therapies..$^{[7-11]}$ In this article, we review different aspects of imaging and involvement patterns of CC in various CNS demyelinating disorders to determine more helpful ways of discrimination of such diseases and also, to demonstrate the role of white matter lesions (particularly in CC) in evaluation of prognosis of these demyelinating disorders. ${ }^{[12-16]}$ To our knowledge there was no article previously, discussing and comparing $\mathrm{CC}$ features in different CNS demyelinating disorders similar to ours.

\section{NORMAL CC}

\section{Anatomy}

The CC is a prominent band of compact white matter composed of transversely oriented nerve fibers by which every part of one hemisphere is connected with corresponding part of the other hemisphere.
It comprises four parts: (1) the reflected anterior portion, or the rostrum; (2) the genu, or the anterior bulbar end; (3) the splenium, or the posterior rounded end; (4) the body, which lies between the genu and the splenium. The anterior half of human CC (genu, rostrum, body) contains fibers interconnecting frontal association cortical areas and the isthmus mostly contains primary motor, somatosensory and auditory fibers. In the splenium, primary visual, association temporooccipital and parietal commissural fibers are mixed, forming a single segment with the hippocampal commissure through which parahippocampal fibers cross. Large diameter fibers are densest in the isthmus and the posterior splenium, whereas small fibers are more numerous in the genu and anterior splenuim. The MR imaging characteristics of $\mathrm{CC}$ are similar to those of white matter: high signal intensity on T1 weighted images and low signal intensity relative to gray matter on both T2 weighted and proton densityweighted images. Measurement in the mid-sagital plane has been subject to extensive investigations. Normal MR imaging features of CC were reported by Okamoto et al. ${ }^{[17]}$ They showed focal thinning is seen superiorly at the junction of body and splenium in $25 \%$ of healthy individuals and considered to be a normal variation. On axial sections parallel to canthomeatal line at the high ventricular level, the body of CC is sectioned longitudinally, displaying a broad band of white matter bordered by the upper outer corners of lateral ventricles.

\section{Function}

The function of the $\mathrm{CC}$ has been investigated for centuries, suggesting it's correlation with intelligence. The earliest studies during the 16th century believed it to be the "seat of the soul". It took until the 18th century for Franz Joseph Gall and Johann Spurzheim, dissecting alcohol fixed brains, to describe bundles of axons passing through the callosal white matter and connecting the 2 hemisphere. It's known functions include: (1) inter-hemispheric exchange of information; (2) facilitation of some cortical activities; (3) inhibition of some cortical functions and integration of inputs reaching one or both hemispheres.

One of the latest contributions in assessment of physiology and function of the CC in different analytical studies is functional MRI. ${ }^{[18-20]}$

\section{IN MULTIPLE SCLEROSIS}

\section{MRI}

MS is the most common autoimmune disease of the CNS and it's characterized by inflammation, demyelination and degenerative changes. The CC 
is one of the common sites of brain involved in MS patients. In MS, we can observe characteristic macroscopic changes in conventional MRI, including: (1) CC atrophy; (2) MS plaques; (3) signal changes within callososeptal interface. ${ }^{[6]} \mathrm{MS}$ plaques mostly occur in the body of the CC, as suggested by some studies. ${ }^{[21-25]}$ Diffuse atrophy of the CC is believed to be a part of general cerebral atrophy in long standing cases or it can be caused by wallerian degeneration and loss of axons within the CC. ${ }^{[26]}$ According to the study by Chen et al., ${ }^{[6]}$ MRI findings can have a big role in discrimination between MS and other demyelinating disorders, in particular MS and Neuromyelitis optica. In this study in which sagittal T2 flair images with $2 \mathrm{~mm}$ thickness were obtained from 23 patients with neuromyelitis optica (NMO), 42 patients with MS and 27 controls, results showed that subcallosal dashdot sign was much more common in opticospinal MS patients than NMO. Contrary to the subcallosal dashdot sign, subcallosal striations had no meaningful difference between $\mathrm{MS}$ and other two groups. ${ }^{[6]}$ According to some studies, MS lesions of $\mathrm{CC}$ found to be small, at the lower border of CC next to the septum pellucidum and crossed the midline asymmetrically. On the other hand, ADEM causes individually large, asymmetric lesions and involvements in marchiafava bignami disease were large, often symmetrically in the midline of the splenium and did not reach the edge of the CC..$^{[5,27]}$ Central CC volume along with medulla oblongata volume can help discriminate between different subtypes of MS. Various subtypes of MS affect different neuroanatomical regions of the CC differently. Most of the patients with secondary progressive MS had central CC with the volume of less than $55 \mathrm{~mm}$, while patients with primary progressive MS had more CC volume centrally. ${ }^{[28]}$

\section{Functional MRI}

Although MRI is the gold standard imaging for evaluation of MS brain lesions, more recent MR techniques helped in exploring axonal loss, wallerian degeneration and microscopic changes in detail. DTI is promising technique for detecting structural changes in MS lesions and revealing microscopic changes in NAWM and Normal appearing gray matter (NAGM). Using water diffusion as a basis to construct anatomic details, DTI offers the potential to identify structural and functional adaptations before gross anatomical changes. Most important DTI parameters are Mean diffusion (MD) and FA. There are also some other parameters in the matter of directional diffusivity such as: radial and axial diffusivity, which have been used by many recent studies. ${ }^{[15,25,26,28]}$ Such parameters interestingly found to be helpful in detecting microscopic and structural changes in lesional and NAWM. Most of recent studies showed increased $A D C$ and reduced FA in both pathologic and NAWM. ${ }^{[29-33]}$ Sigal et al. ${ }^{[11]}$ used DTI to investigate CC integrity in MS patients and age matched controls. In agreement with other studies, ${ }^{[15,26,28,31]}$ MS patients had significant reduction in CC 's FA compared with control group in all subregion of $\mathrm{CC}$, indicating axonal loss and dysfunction in callosal fibers. Most recent studies agree on the fact that in MS patients all MRI indices and parameters are altered pathologically especially in the CC structure. ${ }^{[34]}$ In the study by Farber et al. ${ }^{[35]}$ ADC was found to be helpful as a great parameter for differentiation between MS and other demyelinating diseases, as ADC was found to be significantly elevated in CC in MS patients compared to control group and patients with ADEM disease. ${ }^{[35]} \mathrm{A}$ study by Ozturk et al. ${ }^{[13]}$ showed all MRI indices were diffusely abnormal in the CC. In this study both FA and magnetization transfer ratio (MTR) were decreased and mean and directional diffusivity were increased, but it is to be said that MTR and FA had greatest difference between disease and control group. By spatially tract profile analysis they localized the most abnormal segments in the body and isthmus, with relative sparing of the rostrum and genu. ${ }^{[13]}$

\section{CC as a prognosis indicator}

Quantitative MRI abnormalities in the CC partially account for cognitive and upper/lower extremity dysfunction in MS and ultimately the prognosis. Since cognitive disability is particularly difficult to measure at bedside, and because cognitive and non-cognitive disability may proceed at different rates, the ability to associate cognitive impairment with imaging data may be useful for monitoring patients and assessment of response to therapy in clinical trials. Previous studies in MS have shown significant correlation between cognitive status and CC microstructure. ${ }^{[11,36-38]}$ There has been also studies about the relationship between CC involvement's patterns and prognosis of MS. ${ }^{[7-11]}$ Most of them showed that the damage to white matter network especially CC contributes to the reduced processing speed in task specific abilities. ${ }^{[39]}$ A significant increase in CC's MD was observed in relapsing remitting $M S$, even in benign form. ${ }^{[40-44]}$ Moreover, patterns of tract FA reduction for cognitive test, including localization of lesions in the body and splenium of the CC, only partially overlapped with $\mathrm{T} 2$ lesions, supporting that NAWM abnormality contributes to cognitive dysfunction. In the study by Rimkus et al. ${ }^{[45]}$ results showed correlation between mean diffusion and radial diffusivity, and expended disability status scale (EDSS), suggesting possible relationship between callosal demyelination and sensory motor dysfunction. The cognitive dysfunction was concomitant with DTI changes in CC. MS group of patients showed decreased 
FA and increased MD compared to the matched control group, which can be interpreted as loss of complexity in the white matter tracts in the initial pathological process. As a conclusion, the microstructural changes of CC can be helpful in determination of prognosis in MS patients. They also found that macroscopic changes of $\mathrm{CC}$ had no direct association with cognitive dysfunction in such patients. ${ }^{[45]}$ There were also some studies like study by Natarajan et al. ${ }^{[46]}$ in which they found that the most abnormal DTI indices were present in secondary progressive MS patients. According to a longitudinal cohort study in 2012 CC atrophy of 6 months could predict clinically definite MS within 2 years. It showed that faster decrease in CC cross sectional area and higher T2 lesion volume indicated a poorer prognosis. ${ }^{[35]}$ DTI directional diffusivity may offer the potential to monitor therapeutic options and further understanding of the disease process and prognosis. In a DTI study looking at longitudinal changes in brain tissues in a group of patients with MS receiving Natalizumab therapy, the authors found increased FA, decreased radial diffusivity and no change in axial diffusivity in gadolinium enhancing lesions over the course of therapy. On the other hand, in normal appearing brain tissue, CC's FA and axial diffusivity demonstrated further decline over time, while no significant change in radial diffusivity was observed. ${ }^{[47]}$ Hence, the decline in axial diffusivity may suggest involvement of axonal loss and degeneration in normal appearing brain tissue at the early stage before active lesions develop, possibly attributing to poorer prognosis and progressive disability often observed in MS patients despite treatment. Many recent studies agree on the fact that longitudinal changes are most rapid in CC area of the brain in MS disorder in different types of imaging. ${ }^{[16,19,35,43]}$

\section{IN ACUTE DISSEMINATED ENCEPHALOMYELITIS}

\section{MRI}

Acute disseminated encephalomyelitis is an uncommon immune mediated inflammatory demyelinating disease of the CNS. It is usually a monophasic illness, which may occur after vaccination, viral infection, in association with rheumatic fever, or with unrecognized antecedent disorder. The clinical picture is widespread CNS disturbance, including: drowsiness, coma, multifocal neurological signs and seizure due to involvement of the brain, spinal cord and optic nerves. Radiologic findings of ADEM are usually not pathognomonic. As a result, the differentiation of diagnosis is always difficult. Pathologic findings of ADEM are usually due to: (1) vascular damage; (2) circulating immune complex deposition; (3) complement activation and some other mechanisms yet to be investigated in further studies. ${ }^{[48,49]}$ This changes lead to an alteration of the blood brain barrier, which becomes visible by contrast enhancement in CT and MRI. Increasing T1 and T2 times are also observed and many studies agree on the fact that contrast enhancement are dominantly present in acute phase of the disease and fade out as the acute stage is passed. These studies also showed that the probable underlying causes for hyper intense lesions of brain and spinal cord may be edema and demyelination. ${ }^{[48,50,51]}$ The most important common features of white matter involvement is symmetric periventricular and callosal hyper intense lesions on T2 weighted and flair images as a result of edema and demyelination. As a common finding, many studies showed that most of the ADEM patients $(78 \%)$ have absolute or relative periventricular sparing which was found to be a typical characteristic of ADEM in MRI. Some studies suggested that MRI involvement of CC in ADEM patients can be multiple or single, especially in the splenium of the CC. They also showed that all callosal lesions can be enhanced or not, in MRI (with $\mathrm{Gd}$ ). Generally, the greatest difference between MS and ADEM is that, the likelihood of CC involvement in $\mathrm{MS}$ is far more common than ADEM $(\sim 60 \%$ vs. $\sim 15 \%) .{ }^{[5,52]}$

\section{Functional MRI}

ADEM predominantly affects white matter. It was reported that functional MRI parameters (axial and radial diffusivity) can estimate the extent of myelin injury in the CNS white matter. Although first studies on patients of ADEM showed elevated ADC and reduced FA, Further exploration of directional diffusivity revealed unchanged axial diffusivity and markedly increased radial diffusivity, suggestive of demyelination. These findings were consistent with findings of study by Petzold et al., ${ }^{[53]}$ which showed patients of ADEM having elevated ADC in sub-acute phase and reduced ADC in acute phase. Many other studies agree on this DTI changes in patients with ADEM disorder. Tillema et al. ${ }^{[5]}$ did a retrospective DTI study looking at non-lesional white matter changes within central fibers of the CC's genu and internal capsule in pediatric MS and ADEM. They found lower FA values, increased radial diffusivity and no difference in axial diffusivity in patients with ADEM while in patients with MS results were significantly different (decreased FA and increased radial diffusivity). ${ }^{[5]}$

\section{CC as a prognosis indicator}

Patients with ADEM are usually presented with variable neurologic signs especially after an infectious episode. $\mathrm{MRI}$ is the technique of choice to show these lesions 
and also to illustrate possible prognostic criteria in imaging aspect of such diseases. In some studies, it has been suggested that diffusion weighted imaging (DWI) of CC may not be helpful in determination of prognosis in patients of ADEM, on the other hand, Donmez et al. ${ }^{[51]}$ suggested that brainstem involvement in ADEM disease may have an influence on the prognosis of the disorder, correspondent to the studies showing beneficial use of ADC parameters in prediction of motor disabilities. Combined use of clinical and radiologic findings are needed to predict the chance of relapse in patients suffering from ADEM. Patients with large demyelinating lesions may have more degree of disabilities evaluated by EDSS but they have an excellent response to therapy. It was showed that size of the lesions is not a direct indicator of poor prognosis. According to what we found in different studies on "ADEM prognosis" there is no certainty on how useful are MRI features to predict outcome of ADEM and there are yet more studies to explore this area of research.

\section{IN DEVIC'S NEUROMYELITIS OPTICA}

\section{MRI}

Neuromyelitis optica is a CNS demyelinating disease causing acute transverse myelitis with bilateral optic neuropathy. Paraplegia and blindness are possible complications. There is no definite imaging criteria to distinguish NMO from other demyelinating disorders such as MS and ADEM. ${ }^{[54,55]}$ Irrelative of what is found in $C C$ that will be discussed further in this article general distinguishing findings of MRI in such diseases are: midbrain lesions in the ventral part with poorly defined margins for ADEM vs. Medulla lesions in the dorsal part with poorly defined shape for $\mathrm{NMO}$, and pons lesions with well-defined shape for MS (as the most common sites of involvement). CC involvement is more common in MS in comparison to NMO but there are also some involvement pattern differences to be pointed out. CC lesions in NMO are mostly evident in acute phase of disease and they have generally some similar characteristics. They are usually multiple, edematous and heterogeneous in intensity, while in chronic stage, lesions shrink and disappear. In MS, lesions are small, non-edematous, and the intensity is homogenous in the acute phase and they are more commonly located at lower margin of CC. ${ }^{[56-59]}$ As Chen et al. ${ }^{[6]}$ showed in their study, subcallosal dash dot sign was helpful as it was more common in patient with MS than in the NMO. In another study by Makino et al., ${ }^{[36]}$ it was showed that involvement of splenium of CC in NMO patients was more common than the involvement of the same area in patients with MS $(57 \%$ vs. $27 \%)$. The lesions in NMO also tended to spread from the lower to upper parts of CC. They also found out that lesions in NMO were much more heterogeneous than in MS. ${ }^{[36]}$

\section{Functional MRI}

As we previously pointed out, functional MRI and DTI method of imaging are more helpful in exploration of microstructural and functional changes, especially in NAWM in demyelinating disorders from the aspects of discrimination and diagnosis. According to the study by Kimura et al. ${ }^{[58]}$ in patients with NMO, damage to extensive regions of NAWM has been observed. To investigate this possibility that microstructural alterations are present in these WM tracts, DTI should be applied. According to this study findings FA was decreased in splenium of CC and left optic radiate. In another study focused on DTI features of NAWM in NMO patients which was performed by Jeantroux et al., ${ }^{[59]}$ it was showed that ADC was increased and FA was decreased in NMO patients in posterior limb of internal capsule and optic radiation and spinal cord NAWM. FA had the best correlation with EDSS. FA was lower in spinal cord lesions. In contrast there was no difference between two groups, neither in the anterior limb of internal capsule nor in the CC. These results suggest that NAWM outside the tracts mentioned above remained normal, showing that infralesional abnormality is not usually seen in NMO in contrast to the MS disease. ${ }^{[59]}$ These findings are consistent with the findings by Sun et al., ${ }^{[60]}$ in which they found the similar results suggesting that DTI parameters (mean diffusivity and lambda1) were unchanged in CC region. This field of study needs further investigations yet to determine the distinguishing patterns and parameters in NAWM, especially callosal region in NMO patients. ${ }^{[61,62]}$

\section{$\mathrm{CC}$ as a prognosis indicator}

A combination of biomarkers, neuroimaging data and clinical symptoms are needed to predict prognosis of NMO. It is difficult to consider callosal tract features of neuroimaging as the only indicator of disease outcome. In many studies DTI parameters, especially FA, showed to have the closest correlation with EDSS. As a result, it can be helpful in measuring disease outcome and disability. $\mathrm{He}$ et al. ${ }^{[63]}$ showed decreased FA and increased $A D C$ of $C C$, especially during the acute phase of the disease, plays an important role in the anticipation of cognitive dysfunction and clinical outcome. The researchers have compared regional measures of patients with stable and acute NMO with healthy patients. Both acute and stable NMO patients had a higher average FA in regions of interest of the thalamus and putamen. Acute NMO patients had significantly higher average MDs than controls in the genu of the $\mathrm{CC}$ and optic radiation, and significantly 
lower average MDs in medulla oblongata, internal capsule and thalamus. ${ }^{[64]}$

\section{IN SUSAC SYNDROME}

\section{MRI}

Susac's syndrome (SS) is a clinical triad of encephalopathy, branch retinal artery occlusion and sensorineural hearing loss. It is sometimes misdiagnosed because of similarities with ADEM and MS. Typical triad is not commonly seen. ${ }^{[65]}$ Brain is the main target organ for SS, which makes MRI the best diagnostic test. Susac syndrome mostly causes micro-infarction in both gray and white matter. This can cause hyperintense lesions at any area of the brain, including CC. Micro-infarctions in SS have two specific patterns on MRI: "snowball lesions", in central parts of CC, and "string of pearls", which is commonly seen in internal capsule. ${ }^{[22,66]}$ Raets et al. ${ }^{[67]}$ showed that the combination of typical central callosal lesions with string of pearls is pathognomonic for SS. Encephalopathic SS always involves CC. Snow ball lesions evolve to central callosal holes in the course of the disease. A pathognomonic change in postencephalopathic phase of SS disease is linear defects in central part of CC called "smokes". ${ }^{[67]}$ As reported, CC involvement plays a critical role in early diagnosis of SS and demands aggressive therapy. In severely affected patients, atrophy of cerebellum is usually seen during sub-acute and chronic phase. Correspondent to what stated previously, Mateen et al. ${ }^{[68]}$ demonstrated a series of cases of SS with $79 \%$ involvement rate of CC. CC can be of significant help to distinguish SS from other demyelination disorders of CNS. They showed CC involvement in SS is typically in the central part of the CC.

\section{Functional MRI}

Kleffner et al. ${ }^{[69]}$ showed the most specific finding of DTI in SS patients, was $25 \%$ reduction of FA in genu of Corpus callosum. Reduced fractional anisotropy in the prefrontal areas of the brain was also observed; while in MS patients, it was mainly seen in the body, rostrum and splenium of CC. DTI is considered a useful method to detect microstructural damage based on FA. ${ }^{[69]} \mathrm{FA}$ reflects the spatial directionality of water diffusion, which is decreased in white matter damage; contrary to normal diffusion in conventional MRI of CC and prefrontal area. This puts more emphasis on how essential are new methods of Imaging in neuroimaging exploration of CC disorders.

\section{CC as a prognosis indicator}

In spite of lack of knowledge on this specific subject, some studies pointed out that FA reduction and involvement of genu of the $\mathrm{CC}$ can be useful to predict the outcome of the disorder. The more decrease in FA, the more complication is expected in the course of the disease. There were also some evidences showing that serial DTI parameters can play a role in prediction of outcome and prognosis of the disease but, there are many aspects to be studied and explored yet in this field of research. ${ }^{[60,63,70-72]}$

\section{OTHER DEMYELINATING DISORDERS}

\section{Marchiafava bignami}

MBD disease is a rare form of toxic demyelination of CC associated with chronic alcohol consumption. Several MRI findings have shown lesions not only in the CC but also in the hemispheric white matter. General pattern of $\mathrm{CC}$ pathology in MBD is hyperintensity on flair imaging and sometimes hemispheric white matter, reflecting damage to myelin and vasogenic edema of the $\mathrm{CC}$ and extracallosal projections. ${ }^{[27]}$ Because of pathological variety of this disorder there is no certain sequence and pattern of pathology of CC in MBD. Some studies showed that involvement of the CC in MBD was initially in the genu, without significant association with DTI changes of CC and NAWM. Afterward, there would be some changes in the splenium of $\mathrm{CC}^{\left[{ }^{[73]}\right.}$ The most probable reason why DTI changes were not associated with initial changes in the genu of $\mathrm{CC}$ is that the changes were mostly due to vasogenic edema and that the lesion then converted into cytotoxic edema process. Serial MRI and DTI method of evaluation in MBD cases have been found to be significantly helpful and that's why there will be a great need for further studies on this method of evaluation for such demyelinating disorders. ${ }^{[27]}$ It suffices to briefly review MBD data because there is still significant potential for further new neuroimaging methods for such a rare disease and our main goal in this review is demyelinating diseases with autoimmune nature rather than the disorders caused by environmental factors.

\section{Infectious demyelinating disorders}

Many CNS disorders can cause secondary demyelination as an early or late complication. One major category of CNS diseases, are infective ones. To show the importance of CC in CNS involvement of such disease, a brief review is presented. Infective demyelinating diseases, such as subacute sclerosing panencephalitis (SSPE), streptococcus meningitis, Lyme disease, etc. can involve CC with various patterns. For instance, in SSPE lesions are mostly asymmetric, bilateral and T2-hyperintense and involve the temporal and parietal lobes in the acute stage. No specific pattern of involvement regarding the CC is reported to date, although some case reports 
Table 1: Summary of changes in corpus callosum in different demyelinating diseases and their role in determination of prognosis

\begin{tabular}{|c|c|c|c|c|c|}
\hline & MS & ADEM & NMO & Susac & MBD \\
\hline MRI & $\begin{array}{l}\text { All parts of CC } \\
\text { (mostly body) } \\
\text { plaques and then } \\
\text { possible atrophy/ } \\
\text { small, at the lower } \\
\text { border of CC } \\
\text { crossing the midline } \\
\text { asymmetrically }\end{array}$ & $\begin{array}{l}\text { Mostly in splenium } \\
\text { of CC (widespread } \\
\text { lesions in brain, } \\
\text { mostly sparing } \\
\text { periventricular area) }\end{array}$ & $\begin{array}{l}\text { Multiple } \\
\text { heterogeneouslesions/ } \\
\text { less common involvement } \\
\text { of CC/mostly no lesions in } \\
\text { chronic stage }\end{array}$ & $\begin{array}{l}\text { Snowball lesions in } \\
\text { central CC/linear } \\
\text { defects called } \\
\text { "smoke" in central } \\
\text { CC during post- } \\
\text { encephalic phase }\end{array}$ & $\begin{array}{l}\text { Acutely involves } \\
\text { genu and then } \\
\text { splenium of CC/ } \\
\text { large, often } \\
\text { symmetrical, in } \\
\text { the midline of the } \\
\text { splenium, does } \\
\text { not reach the } \\
\text { edge of the CC }\end{array}$ \\
\hline fMRI & $\begin{array}{l}\text { Significant increase } \\
\text { in ADC (MD)/ } \\
\text { decreased FA }\end{array}$ & $\begin{array}{l}\text { Increased ADC (AD } \\
\text { and RD) in sub-acute } \\
\text { phase but decreased } \\
\text { ADC in acute phase/ } \\
\text { decreased FA }\end{array}$ & $\begin{array}{l}\text { Mostly unchanged } \\
\text { parameters in CC. If seen: } \\
\text { increased } A D C / \text { decreased } \\
\text { FA in CC and optic } \\
\text { radiation }\end{array}$ & $\begin{array}{l}\text { Decreased FA in } \\
\text { genu of CC }\end{array}$ & $\begin{array}{l}\text { Mostly no } \\
\text { significant } \\
\text { changes }\end{array}$ \\
\hline Prognosis & $\begin{array}{l}\text { Increased MD/ } \\
\text { decreased } \mathrm{FA}=\text { more } \\
\text { disability }\end{array}$ & $\begin{array}{l}\text { Increased } A D C= \\
\text { more disability }\end{array}$ & $\begin{array}{l}\text { Increased ADC and } \\
\text { decreased FA are helpful } \\
\text { in acute phase }\end{array}$ & $\begin{array}{l}\text { FA change and } \\
\text { genu involvement } \\
=\text { more disability }\end{array}$ & $\begin{array}{l}\text { No certain } \\
\text { evidences are } \\
\text { available }\end{array}$ \\
\hline
\end{tabular}

MS: multiple sclerosis; ADEM: acute disseminated encephalomyelitis; MBD: marchiafava bignami; MRI: magnetic resonance imaging; CC: corpus callosum; FA: fractional anisotropy; ADC: apparent diffusion coefficient; MD: mean diffusion; NMO: neuromyelitis optica; AD: axial diffusivity; RD: radial diffusivity

presented splenium involvement. ${ }^{[7]}$ Streptococcus meningitis caused by group B streptococcus results in brain infarction as it's main mechanism of action. It disrupts blood supply to thalamus, periventricular white matter and basal ganglia. Although, there have been case reports demonstrating involvement of callosal splenium in this disorder but to our knowledge no solid study investigated changes of inter-hemispheric fibers in detail. Borrelia burgdorferi is the pathogen causing Lyme disease, which is commonly mistaken for MS. General patterns of CC lesions are seen in Lyme disease. Fluid-attenuated inversion recovery and T2 weighted MRI are the most efficient ones to explore such lesions. ${ }^{[75]}$

$\mathrm{CC}$ can be demyelinated in many other disorders which are not primarily demyelinating. Neurodegenerative diseases are one of the most important instances to cause CC demyelination as a long term complication, However because $\mathrm{CC}$ damage is not the distinguishing feature of such disorders, it is out of the scope of this study to evaluate this group of CNS disorders.

\section{CONCLUSION}

As summarized in the Table 1, this study demonstrates that neuroimaging of white matter, especially callosal area of brain, plays an important role in distinguishing many demyelinating diseases from one another. We should focus on many new neuroimaging methods, such as DTI, fMRI, etc. to investigate more possible ways of further evaluation and pattern comparison in such disorders. Additional data are clearly needed if we are to gain further insight into callosal pathological pattern's map and to establish practical ways for application of CC differences in diagnosis of various CNS demyelinating disorders.

\section{Authors' contributions}

Analysis and interpretation of data: A. Neshatfar Study conception and design: M. Etemadifar

Revision and data collection consultant: A.A. Zamani Data collection: M. Salari

\section{Financial support and sponsorship None.}

\section{Conflicts of interest}

There are no conflicts of interest.

\section{Patient consent}

There is no patient data involved.

\section{Ethics approval \\ Not applicable.}

\section{REFERENCES}

1. De Stefano N, Stromillo ML, Giorgio A, Bartolozzi ML, Battaglini M, Baldini M, Portaccio E, Amato MP, Sormani MP. Establishing pathological cut-offs of brain atrophy rates in multiple sclerosis. $J$ Neurol Neurosurg Psychiatry 2016;87:93-9.

2. Uchino A, Takase Y, Nomiyama K, Egashira R, Kudo S. Acquired lesions of the corpus callosum: MR imaging. Eur Radiol 2006;16:905-14.

3. Friese SA, Bitzer M, Freudenstein D, Voigt K, Küker W. Classification of acquired lesions of the corpus callosum with MRI. Neuroradiology 2000;42:795-802.

4. Arenth PM, Russell KC, Scanlon JM, Kessler LJ, Ricker JH. Corpus callosum integrity and neuropsychological performance after traumatic brain injury: a diffusion tensor imaging study. $J$ Head Trauma Rehabil 2014;29:E1-10.

5. Tillema JM, Leach J, Pirko I. Non-lesional white matter changes in 
pediatric multiple sclerosis and monophasic demyelinating disorders. Mult Scler 2012;18:1754-9.

6. Chen Z, Feng F, Yang Y, Li J, Ma L. MR imaging findings of the corpus callosum region in the differentiation between multiple sclerosis and neuromyelitis optica. Eur J Radiol 2012;81:3491-5.

7. Deppe M, Tabelow K, Krämer J, Tenberge JG, Schiffler P, Bittner S, Schwindt W, Zipp F, Wiendl H, Meuth SG. Evidence for early, nonlesional cerebellar damage in patients with multiple sclerosis: DTI measures correlate with disability, atrophy, and disease duration. Mult Scler 2016;22:73-84.

8. Granberg T, Martola J, Bergendal G, Shams S, Damangir S, Aspelin P, Fredrikson S, Kristoffersen-Wiberg M. Corpus callosum atrophy is strongly associated with cognitive impairment in multiple sclerosis: results of a 17-year longitudinal study. Mult Scler 2015;21:1151-8.

9. Damasceno A, Damasceno BP, Cendes F. Subclinical MRI disease activity influences cognitive performance in MS patients. Mult Scler Relat Disord 2015;4:137-43.

10. Yaldizli Ö, Penner IK, Frontzek K, Naegelin Y, Amann M, Papadopoulou A, Sprenger T, Kuhle J, Calabrese P, Radü EW, Kappos L, Gass A. The relationship between total and regional corpus callosum atrophy, cognitive impairment and fatigue in multiple sclerosis patients. Mult Scler 2014;20:356-64.

11. Sigal T, Shmuel M, Mark D, Gil H, Anat A. Diffusion tensor imaging of corpus callosum integrity in multiple sclerosis: correlation with disease variables. $J$ Neuroimaging 2012;22:33-7.

12. Brown LN, Zhang Y, Mitchell JR, Zabad R, Metz LM. Corpus callosum volume and interhemispheric transfer in multiple sclerosis. Can J Neurol Sci 2010;37:615-9.

13. Ozturk A, Smith SA, Gordon-Lipkin EM, Harrison DM, Shiee N, Pham DL, Caffo BS, Calabresi PA, Reich DS. MRI of the corpus callosum in multiple sclerosis: association with disability. Mult Scler 2010;16:166-77.

14. Comi G, Filippi M, Martinelli V, Sirabian G, Visciani A, Campi A, Mammi S, Rovaris M, Canal N. Brain magnetic resonance imaging correlates of cognitive impairment in multiple sclerosis. J Neurol Sci 1993;115 Suppl:S66-73.

15. Genova HM, DeLuca J, Chiaravalloti N, Wylie G. The relationship between executive functioning, processing speed, and white matter integrity in multiple sclerosis. J Clin Exp Neuropsychol 2013;35:631-41.

16. Llufriu S, Blanco Y, Martinez-Heras E, Casanova-Molla J, Gabilondo I, Sepulveda M, Falcon C, Berenguer J, Bargallo N, Villoslada P, Graus F, Valls-Sole J, Saiz A. Influence of corpus callosum damage on cognition and physical disability in multiple sclerosis: a multimodal study. PLoS One 2012;7:e37167.

17. Okamoto K, Ito J, Tokiguchi S. The MRI findings on the corpus callosum of normal young volunteers. Nihon Igaku Hoshasen Gakkai Zasshi 1990;50:954-63.

18. Giorgio A, Palace J, Johansen-Berg H, Smith SM, Ropele S, Fuchs S, Wallner-Blazek M, Enzinger C, Fazekas F. Relationships of brain white matter microstructure with clinical and MR measures in relapsing-remitting multiple sclerosis. J Magn Reson Imaging 2010;31:309-16.

19. Fling BW, Bernard JA, Bo J, Langan J. Corpus callosum involvement and bimanual coordination in multiple sclerosis. $J$ Neurosci 2008;28:7248-9.

20. Kern KC, Sarcona J, Montag M, Giesser BS, Sicotte NL. Corpus callosal diffusivity predicts motor impairment in relapsing-remitting multiple sclerosis: a TBSS and tractography study. Neuroimage 2011;55:1169-77.

21. Gutierrez J, Issacson RS, Koppel BS. Subacute sclerosing panencephalitis: an update. Dev Med Child Neurol 2010;52:901-7.

22. Freua F, Lucato LT, Villela F, Rabello GD. Susac syndrome. Arq Neuropsiquiatr 2014;72:812-3.

23. Yaldizli Ö, Glassl S, Sturm D, Papadopoulou A, Gass A, Tettenborn B, Putzki N. Fatigue and progression of corpus callosum atrophy in multiple sclerosis. J Neurol 2011;258:2199-205.

24. Orije J, Kara F, Guglielmetti C, Praet J, Van der Linden A, Ponsaerts $\mathrm{P}$, Verhoye M. Longitudinal monitoring of metabolic alterations in cuprizone mouse model of multiple sclerosis using $1 \mathrm{H}$-magnetic resonance spectroscopy. Neuroimage 2015;114:128-35.

25. Warlop NP, Fieremans E, Achten E, Debruyne J, Vingerhoets G. Callosal function in MS patients with mild and severe callosal damage as reflected by diffusion tensor imaging. Brain Res 2008;1226:218-25.

26. Pelletier J, Habib M, Lyon-Caen O, Salamon G, Poncet M, Khalil R. Functional and magnetic resonance imaging correlates of callosal involvement in multiple sclerosis. Arch Neurol 1993;50:1077-82.

27. Paidipati Gopalkishna Murthy K. Magnetic resonance imaging in marchiafava-bignami syndrome: a cornerstone in diagnosis and prognosis. Case Rep Radiol 2014;2014:609708.

28. Roosendaal SD, Geurts JJ, Vrenken H, Hulst HE, Cover KS, Castelijns JA, Pouwels PJ, Barkhof F. Regional DTI differences in multiple sclerosis patients. Neuroimage 2009;44:1397-403.

29. Van Hecke W, Nagels G, Leemans A, Vandervliet E, Sijbers J, Parizel PM. Correlation of cognitive dysfunction and diffusion tensor MRI measures in patients with mild and moderate multiple sclerosis. $J$ Magn Reson Imaging 2010;31:1492-8.

30. Fink F, Klein J, Lanz M, Mitrovics T, Lentschig M, Hahn HK, Hildebrandt $\mathrm{H}$. Comparison of diffusion tensor-based tractography and quantified brain atrophy for analyzing demyelination and axonal loss in MS. J Neuroimaging 2010;20:334-44.

31. Rueda F, Hygino LC Jr, Domingues RC, Vasconcelos CC, PapaisAlvarenga RM, Gasparetto EL. Diffusion tensor MR imaging evaluation of the corpus callosum of patients with multiple sclerosis. Arq Neuropsiquiatr 2008;66:449-53.

32. Rashid W, Hadjiprocopis A, Davies G, Griffin C, Chard D, Tiberio M, Altmann D, Wheeler-Kingshott C, Tozer D, Thompson A, Miller DH. Longitudinal evaluation of clinically early relapsingremitting multiple sclerosis with diffusion tensor imaging. $J$ Neurol 2008;255:390-7.

33. Hasan KM, Gupta RK, Santos RM, Wolinsky JS, Narayana PA. Diffusion tensor fractional anisotropy of the normal-appearing seven segments of the corpus callosum in healthy adults and relapsingremitting multiple sclerosis patients. J Magn Reson Imaging 2005;21:735-43.

34. Coombs BD, Best A, Brown MS, Miller DE, Corboy J, Baier M, Simon JH. Multiple sclerosis pathology in the normal and abnormal appearing white matter of the corpus callosum by diffusion tensor imaging. Mult Scler 2004;10:392-7.

35. Straus Farber R, Devilliers L, Miller A, Lublin F, Law M, Fatterpekar G, Delman B, Naidich T. Differentiating multiple sclerosis from other causes of demyelination using diffusion weighted imaging of the corpus callosum. J Magn Reson Imaging 2009;30:732-6.

36. Makino T, Ito S, Mori M, Yonezu T, Ogawa Y, Kuwabara S. Diffuse and heterogeneous $\mathrm{T} 2$ hyper intense lesions in the splenium are characteristic of neuromyelitis optica. Mult Scler 2013;19:308-15.

37. Damasceno A, Damasceno BP, Cendes F. Subclinical MRI disease activity influences cognitive performance in MS patients. Mult Scler Relat Disord 2015;4:137-43.

38. Hanken K, Eling P, Kastrup A, Klein J, Hildebrandt H. Integrity of hypothalamic fibers and cognitive fatigue in multiple sclerosis. Mult Scler Relat Disord 2015;4:39-46.

39. Zipunnikov V, Greven S, Shou H, Caffo B, Reich DS, Crainiceanu C. Longitudinal high-dimensional principal components analysis with application to diffusion tensor imaging of multiple sclerosis. Ann Appl Stat 2014;8:2175-202.

40. Fink F, Klein J, Lanz M, Mitrovics T, Lentschig M, Hahn HK, Hildebrandt H. Comparison of diffusion tensor-based tractography and quantified brain atrophy for analyzing demyelination and axonal loss in MS. J Neuroimaging 2010;20:334-44.

41. Dachsel RM, Dachsel R, Domke S, Groß T, Schubert O, Kotrini L, Ladegast K, Vogel J, Jordan T, Zawade S. Optic neuropathy after 
retrobulbar neuritis in multiple sclerosis: are optical coherence tomography and magnetic resonance imaging useful and necessary follow-up parameters? Nervenarzt 2015;86:187-96.

42. Rossi F, Giorgio A, Battaglini M, Stromillo ML, Portaccio E, Goretti B, Federico A, Hakiki B, Amato MP, De Stefano N. Relevance of brain lesion location to cognition in relapsing multiple sclerosis. PLoS One 2012; 7:e44826.

43. Bergendal G, Martola J, Stawiarz L, Kristoffersen-Wiberg M, Fredrikson S, Almkvist O. Callosal atrophy in multiple sclerosis is related to cognitive speed. Acta Neurol Scand 2013;127:281-9.

44. Harrison DM, Shiee N, Bazin PL, Newsome SD, Ratchford JN, Pham D, Calabresi PA, Reich DS. Tract-specific quantitative MRI better correlates with disability than conventional MRI in multiple sclerosis. J Neurol 2013;260:397-406.

45. Rimkus Cde M, Junqueira Tde F, Lyra KP, Jackowski MP, Machado MA, Miotto EC, Callegaro D, Otaduy MC, Leite Cda C. Corpus callosum microstructural changes correlate with cognitive dysfunction in early stages of relapsing-remitting multiple sclerosis: axial and radial diffusivities approach. Mult Scler Int 2011;2011:304875.

46. Natarajan R, Hagman S, Wu X, Hakulinen U, Raunio M, Helminen M, Rossi M, Dastidar P, Elovaara I. Diffusion tensor imaging in NAWM and NADGM in MS and CIS. Mult Scler Int 2013;2013:265259.

47. Zipunnikov V, Greven S, Shou H, Caffo B, Reich DS, Crainiceanu C. Longitudinal high-dimensional principal components analysis with application to diffusion tensor imaging of multiple sclerosis. Ann Appl Stat 2014;8:2175-202.

48. Liu JG, Qiao WY, Dong QW, Zhang HL, Zheng KH, Qian HR, Qi $\mathrm{XK}$. Clinical features and neuroimaging findings of 12 patients with acute disseminated encephalomyelitis involved in corpus callosum. Zhonghua Yi Xue Za Zhi 2012;92:3036-41.

49. Brass SD, Caramanos Z, Santos C, Dilenge ME, Lapierre Y, Rosenblatt B. Multiple sclerosis vs acute disseminated encephalomyelitis in childhood. Pediatr Neurol 2003;29:227-31.

50. Senda J, Watanabe H, Tsuboi T, Hara K, Watanabe H, Nakamura R, Ito M, Atsuta N, Tanaka F, Naganawa S, Sobue G. MRI mean diffusivity detects widespread brain degeneration in multiple sclerosis. J Neurol Sci 2012;319:105-10.

51. Donmez FY, Aslan H, Coskun M. Evaluation of possible prognostic factors of fulminant acute disseminated encephalomyelitis (ADEM) on magnetic resonance imaging with fluid-attenuated inversion recovery (FLAIR) and diffusion-weighted imaging. Acta Radiol 2009;50:334-9.

52. Tanaka Y, Nishida H, Hayashi R, Inuzuka T, Otsuki M. Callosal disconnection syndrome due to acute disseminated enchephalomyelitis. Rinsho Shinkeigaku 2006;46:50-4.

53. Petzold GC, Stiepani H, Klingebiel R, Zschenderlein R. Diffusionweighted magnetic resonance imaging of acute disseminated encephalomyelitis. Eur J Neurol 2005;12:735-6.

54. Chanson JB, Lamy J, Rousseau F, Blanc F, Collongues N, Fleury M, Armspach JP, Kremer S, de Seze J. White matter volume is decreased in the brain of patients with neuromyelitis optica. Eur J Neurol 2013;20:361-7.

55. Eshaghi A, Wottschel V, Cortese R,Calabrese M, Sahraian MA, Thompson AJ, Alexander DC, Ciccarelli O. Gray matter MRI differentiates neuromyelitis optica from multiple sclerosis using random forest. Neurology 2016;87:2463-70.

56. Kim JE, Kim SM, Ahn SW, Lim BC, Chae JH, Hong YH, Park KS, Sung JJ, Lee KW. Brain abnormalities in neuromyelitis optica. $J$ Neurol Sci 2011;302:43-8.

57. Granberg T, Bergendal G, Shams S, Aspelin P, Kristoffersen-Wiberg M, Fredrikson S, Martola J. MRI-defined corpus callosal atrophy in multiple sclerosis: a comparison of volumetric measurements, corpus callosum area and index. J Neuroimaging 2015;25:996-1001.

58. Kimura MC, Doring TM, Rueda FC, Tukamoto G, Gasparetto EL. In vivo assessment of white matter damage in neuromyelitis optica: a diffusion tensor and diffusion kurtosis MR imaging study. J Neurol Sci 2014;345:172-5.

59. Jeantroux J, Kremer S, Lin XZ, Collongues N, Chanson JB, Bourre B, Fleury M, Blanc F, Dietemann JL, de Seze J. Diffusion tensor imaging of normal-appearing white matter in neuromyelitis optica. $J$ Neuroradiol 2012;39:295-300.

60. Sun H, Ye J, Liao ZY, Li CJ, You XF, Li KC, Liu YO, Duan YY. The clinical and magnetic resonance imaging studies of brain damages in neuromyelitis optica. Zhonghua Nei Ke Za Zhi 2011;50:193-6.

61. Harrison DM, Caffo BS, Shiee N, Farrell JA, Bazin PL, Farrell SK, Ratchford JN, Calabresi PA, Reich DS. Longitudinal changes in diffusion tensor-based quantitative MRI in multiple sclerosis. Neurology 2011;76:179-86.

62. Sigirli D, Ercan I, Ozdemir ST, Taskapilioglu O, Hakyemez B, Turan OF.Shape analysis of the corpus callosum and cerebellum in female MS patients with different clinical phenotypes. Anat Rec (Hoboken) 2012;295:1202-11.

63. He D, Wu Q, Chen X, Zhao D, Gong Q, Zhou H. Cognitive impairment and whole brain diffusion in patients with neuromyelitis optica after acute relapse. Brain Cogn 2011;77:80-8.

64. Ciccarelli O, Werring DJ, Barker GJ, Griffin CM, Wheeler-Kingshott CA, Miller DH, Thompson AJ. A study of the mechanisms of normalappearing white matter damage in multiple sclerosis using diffusion tensor imaging -- evidence of Wallerian degeneration. J Neurol 2003;250:287-92.

65. Wood ET, Ronen I, Techawiboonwong A, Jones CK, Barker PB, Calabresi P, Harrison D, Reich DS. Investigating axonal damage in multiple sclerosis by diffusion tensor spectroscopy. J Neurosci 2012;32:6665-9.

66. Zito G, Luders E, Tomasevic L, Lupoi D, Toga AW, Thompson PM, Rossini PM, Filippi MM, Tecchio F. Inter-hemispheric functional connectivity changes with corpus callosum morphology in multiple sclerosis. Neuroscience 2014;266:47-55.

67. Saida T. Magnetic resonance imaging in multiple sclerosis. Rinsho Shinkeigaku 1999;39:114-5.

68. Mateen FJ, Zubkov AY, Muralidharan R, Fugate JE, Rodriguez FJ, Winters JL, Petty GW. Susac syndrome: characteristics and treatment in 29 new cases. Eur J Neurol 2012;19:800-11.

69. Kleffner I, Deppe M, Mohammadi S, Schwindt W, Sommer J, Young P, Ringelstein EB. Neuroimaging in Susac's syndrome: focus on DTI. J Neurol Sci 2010;299:92-6.

70. Raets I, Gelin G. Susac's syndrome: a clinical and radiological challenge. JBR-BTR 2012;95:355-6.

71. Rennebohm R, Susac JO, Egan RA, Daroff RB. Susac's syndrome. $J$ Neurol Sci 2010;299:86-91.

72. Zhao DD, Zhou HY, Wu QZ, Liu J, Chen XY, He D, He XF, Han WJ, Gong QY. Diffusion tensor imaging characterization of occult brain damage in relapsing neuromyelitis optica using 3.0T magnetic resonance imaging techniques. Neuroimage 2012;59:3173-7.

73. Star M, Gill R, Bruzzone M, De Alba F, Schneck MJ, Biller J. Do not forget susac syndrome in patients with unexplained acute confusion. $J$ Stroke Cerebrovasc Dis 2015;24:e93-5.

74. Öztürk M, Sığırcı A, Yakıncı C. MRI and MR spectroscopy findings of a case of subacute sclerosing panencephalitis affecting the corpus callosum. BMJ Case Rep 2015;2015:bcr2015209310.

75. Belman AL, Coyle PK, Roque C, Cantos E. MRI findings in children infected by borrelia burgdorferi. Pediatr Neurol 1992;8:428-31. 